bioRxiv preprint doi: https://doi.org/10.1101/2022 03.03.482810; this version posted March 3, 2022. The copyright holder for this preprint (which was not certified by peer review) is the author/funder, who has granted bioRxiv a license to display the preprint in perpetuity. It is made available under aCC-BY-ND 4.0 International license.

\title{
Z-RNA and the flipside of the SARS Nsp13 helicase
}

alan.herbert@insideoutbio.com

Alan Herbert ${ }^{1,2^{*}}$, Alexander Shein ${ }^{2}$ and Maria Poptsova ${ }^{2}$

${ }^{1}$ InsideOutBio, 42 8th Street, Charlestown, MA

${ }^{2}$ Laboratory of Bioinformatics, Faculty of Computer Science, National Research University Higher School of Economics, 11 Pokrovsky Bulvar, Moscow, Russia 101000

*Corresponding author

Keywords: coronavirus;SARS;MERS;Z-RNA;ZBP1;Necoptosis 


\begin{abstract}
We present evidence that the severe acute respiratory syndrome coronavirus (SARS) non-structural protein 13 (Nsp13) modulates the Z-RNA dependent regulated cell death pathway of necroptosis (1). We show that Z-prone sequences (called flipons (2)) exist in coronavirus and provide a signature that enables identification of the animal viruses which have become human pathogens. We also identify a potential RHIM in Nsp13. These two observations allow us to suggest a model in which Nsp13 may regulate Z-RNA-initiated RHIM-dependent cell death outcomes at two steps. The first step involves possible new ATP-independent Z-flipon helicase activity in Nsp13, which is distinct from the activity of the canonical A-RNA helicase. This activity unwinds/quenches nascent Z-RNAs, preventing their sensing by ZBP1. The second step involves RHIM-dependent inhibition of ZBP1, RIPK3 and/or RIPK1, preventing cell death downstream of Z-RNA sensing. Together the RHIM and Z-flipon helicase have the potential to alter the host response to the virus and the effectiveness of drugs targeting the NSP13 helicase.
\end{abstract}




\section{Introduction}

2

Z-RNA and Flipons. The left-handed Z-DNA and Z-RNA conformations form from their right-handed counterparts of B-DNA and A-RNA by flipping the bases over to produce the characteristic zig-zag backbone (3). The energy to produce the flip is produced by processive enzymes such as helicases and polymerases that generate negative supercoiling in their wake. In other situations, the flip reduces topological stress arising when different nucleic acids basepair and become entangled. Sequences that form these left-handed structures under physiological conditions are called flipons and often are composed of alternating pyrimidine and purine residues, such as $(C G)_{n},(C A)_{n}$ and $(U G)_{n}$. The propensity to adopt the Z-conformation can be scored using the ZHUNT3 (ZH3) program (4). Much of the energy cost for forming Z-DNA and Z-RNA is in the creation of junctions between right-handed and left-handed helices. For Z-RNA, the flip occurs more easily when dsRNA contain basepair mismatches, non-canonical basepairs or unpaired residues at both ends of the Z-forming segment (5).

Z-RNA and innate immunity. Z-DNA and Z-RNA are recognized in a conformation specific manner by protein containing the Z $\alpha$ domain that was first discovered in the dsRNA editing enzyme ADAR1 (6), but is also found in many other proteins, including Z-DNA binding protein (ZBP1) and virally encoded proteins like E3 that is encoded by vaccinia virus (7). Interaction between Za proteins regulates the regulated necroptotic cell death pathway $(8,9)$. The pathway is triggered when ZBP1 binds to Z-DNA or Z-RNA and activates receptor interacting protein kinases (RIPKs) 1 and 3, through the RIP homotypic interaction motif (RHIM) shared by all three proteins. RIPK3 then phosphorylates Mixed Lineage Kinase Domain Like (MLKL) pseudokinase, leading to necroptosis, while RIPK1 induces Caspase-8-dependent apoptosis, via the adaptor protein FADD. The RHIM is a $\sim 40$ aa motif, first identified in RIPK1 (10), which contains an $(\mathrm{I} / \mathrm{V}) \mathrm{Q}(\mathrm{I} / \mathrm{L} / \mathrm{V}) \mathrm{G}$ sequence at its core (11). The pathway plays an important role during infection by the negative RNA stranded influenza virus (12), as well as upon infection with the 
24 herpesviruses murine cytomegalovirus (mCMV) and herpes simplex virus (HSV)-1/2 and the poxvirus

25 vaccinia virus (13).

Viruses and ZBP1 dependent necroptosis. Viruses that are prone to form Z-DNA and Z-RNA have

27 developed strategies to regulate ZBP1-dependent necroptosis. These include encoding ZBP1 homologs, such as E3, that compete with ZBP1 for Z-RNA (14). Another strategy by which viruses regulate ZBP1/RIPK signaling is by encoding proteins with RHIMs. So far, only RHIMs produced by DNA viruses like the Herpesviridae mCMV, HSV-1 and HSV-2 are known to play an important role in virulence (15). Notably, no RNA virus has yet been shown to encode a RHIM-containing protein.

\section{Results}

A corona virus-specific Z-flipon signature. We were interested in whether the SARS family coronaviruses might also regulate Z-RNA dependent ZBP1 activation and cell death. We used a twopronged approach. First, we searched for Z-prone sequences in coronavirus using the program ZH3. We were interested in those sequences that altered as the virus adapted to humans. We found that all examined coronaviruses contained sequences that were Z-prone, and that the Z-signature for each strain of virus is unique (Figure 1).Using the signature, it is easy to identify the host animal from which the pathogenic human viruses arose. For example, we show that the signatures for Llama coronavirus (CoV) and Middle East respiratory syndrome (MERS) are identical, as are those for civet CoV and Severe

42 (Figure 1 Panels $A$ and $B$ ).

44 flipping, where a score of around 700 is sufficient to change flipon conformation under physiological conditions. While not experimentally calibrated for the formation of Z-RNA, the scores observed for the 
47 caveat in mind, we observed the loss in the 1ab transcript of a strong Z-forming sequence when comparing SARS1 to SARS2. The reduced ZH3 score in SARS2 is due to three synonymous mutation in adjacent codons that preserve a hairpin sRNA structure and the peptide sequence PARAR (residues 335339 of SARS2 Nsp13). This arginine rich sequence has the potential to bind nucleic acids (figure $2 \mathrm{~A}$ and peptide, PAKAR, has a lysine in place of the first arginine, a conservative substitution. for viral protein containing a RHIM and found that the prototypical VQIG sequence was present in the Nsp13 protein of highly pathogenic human CoVs, but not in other CoVs thought to infect humans (Figure $2 \mathrm{D}$ and $\mathrm{E})$.

The structure of NSP13 helicase. Both strategies focused our attention of the Nsp13 helicase and its potential novel role as a Z-flipon helicase. Nsp13 unwinds both DNA and RNA in the $5^{\prime}->3^{\prime}$ direction. It is a member of the helicase superfamily 1B (SF1B) (17). Along with other CoV encoded proteins, it forms a viral replication-transcription complex. High resolution crystallographic and electron-microscopy structures of NSP13 have recently been published and suggests that a second Nsp13 cooperates with the first to enhance translocation along the CoV genomic RNA (18-20). The Nsp13 helicase has two canonical RecA domains between which ATP is bound and through which single-stranded RNA egresses from the complex. Nsp1 also has three N-terminal domains that are unique to nidovirus helicases. The stalk domain connects a zinc-binding (ZincBD) domain to the 1B domain (Figure 3). surprisingly, the peptide PARA motif, which is in the RecA1 domain, interacts with the RHIM when the Nsp13 is in the ATP-free closed conformation (Figure 3A). In the active conformation, the RHIM and 
separation of the 1B domain from the RecA2 domain renders Nsp13 unable to translocate on RNA (20).

71 The cavity created by this separation appears large enough to accommodate a dsRNA structure (Figure

$723 C)$.

\section{Discussion}

74 The cavity is lined by the residues known to bind single-stranded RNA (ssRNA) (shown by white space fill

75 carbons in figure 4), both to the phosphate backbone and also in a base-specific manner. Into the newly

76 formed cavity projects the PARA peptide, with R337 and R339 forming a hook. Also, tyrosine Y205, along

77 with W178, faces the interior of the cavity. Potentially Y205 and W178 could engage each other in an

78 edge to face configuration similar to that of Y177 and W195 in the Z $\alpha$ domain and enable the

79 conformation-specific recognition of Z-RNA.

80

81

82

83

84

85

86

87 RIPKs.

88 modulate their activities.

Novel Nsp13 flipon helicase activity. Docking Nsp13 to Z-RNA in silico leads us to propose a model where Nsp13 acts as a flipon helicase, preventing Z-RNA formation by capturing single-stranded RNA formed during the flip to and from A-RNA. The strand separation generated is powered by the free energy stored in Z-RNA rather than through ATP hydrolysis. The process of strand capture would be enhanced if Nsp13 had specificity for Z-prone sequences. Indeed, the recent Chen at al structures detail the binding of Nsp13 to an alternating pyrimidine/purine sequence CAUGU substrate (20). Recognition of Z-RNA by Nsp13leading to strand separation would then prevent binding by ZBP1 and activation of

Binding to Z-RNA would also lead to the exposure of the Nsp13 RHIM, which is on the other side of the 1B domain (Figure 3C). Once the RHIM is sprung lose, it is free to contact ZBP1, RIPK1 and RIPK3 and 
92 Disease Implications .At this stage, we only know of the possibilities and hope that the above

93 hypotheses will provide a framework for further investigation of Nsp13 effects on necroptosis in

94 properly qualified BSL3 laboratories. If it is found that pathogenic CoVs do indeed produce Z-RNA (as the ZH3 algorithm predicts) and that the RHIM in Nsp13 regulates ZBP1, RIPK3 and/or RIPK1 signaling, then we suggest that effects will depend on the stage of viral infection. At early stages, suppressing Z-RNA formation and necroptosis would enable increased viral replication. Here flipons may act as a sink for the topological stress arising within the dsRNA formed by template switching during viral transcription and replication \{Chen, $2020 \# 1552\}$. The recognition of Z-RNA by Nsp3 then blocks the viral polymerase until the two RNA strands are fully separated by the classical Nsp13 helicase activity. At later stages of infection, the dsRNA tangles formed as defective viral genomes accumulate may create Nsp13 clusters,

102 leading to the formation of RHIM filaments. The filaments are amyloid like structures capable of 103 activating the RIP necrosome (21) to cause cell death, as recently reported in SARS2 in vitro and in vivo 104 models.

105 Coronavirus and Human Pathology. From our analysis, it seems that the RHIM domain is a requirement for CoV to cause severe pathology in humans. Acquiring a RHIM may be necessary for the successful

107 jump the virus made from its natural host to humans, although not a sufficient one as other mutations 108 that enable engagement of human cell surface receptors are required. The mutations that lead to loss of 109 the strong Z-prone sequence present in SARS1 may have favored spread of SARS2 (Figure 2A and 2B).

110 The potential combination of the RHIM domain with the Z-flipon helicase to modulate the cell death 111 pathways so far appears unique among human viruses and may account for its extreme virulence.

112 The high frequency in humans of protein variants in the necroptotic pathway that affect its function (22) 113 leave some individuals more vulnerable to SARS2 induced cell death. While Nsp13 inhibitors that target 114 the ATP-binding site are likely to be effective in early infection by inhibiting the classical helicase 
115 function, they are unlikely to be effective against the ATP-independent Z-flipon helicase clusters that

116 potentially produce severe pathology at later stages of the disease.

\section{Methods}

118 The Z-forming potential of the Coronavirus sequences were assessed using ZHUNT3 using the following 119 command line "zhunt3nt 126 24" \{Schroth, 1992 \#1415\}. The structures PDB files 7NIO (18), 6XEZ (19) 120 and 7RDX (20) wered visualize using the open access NGLViewer \{Rose, $2015 \# 1541$ \}. Amino acid 121 alignments and the Phylogram were prepared using MUSCLE \{Edgar, $2004 \# 1557\}$ using the following

122 NCBI sequences for MERS (NC_019843.3), SARS (NC_004718.3), SARS2 (NC_045512.2), Hum_CoV-229E

123 (KU291448.1), CoV-OC43 (MW587042.1), CoV_NL63 (MG428706.1), CoV-HKU1 (NC_006577), Bat

124 RaTG13 (MN996532), Civet_PC4-227 (AY613950.1) and Llama (MN507638).

125 Author Contributions. AH is an international supervisor for the HSE Bioinformatics Laboratory run by 126 MP where AS is a student who identified the strong Z-forming segment in SARS1. AH conceptualized and 127 wrote the paper with edits from MP.

128 Acknowledgements. We that Sid Balachandran for suggesting the possibility of RHIM domains in SARS2 129 and for helpful edits to the manuscript.

130 Conflict of Interest. None declared by the authors 
bioRxiv preprint doi: https://doi.org/10.1101/2022.03.03.482810; this version posted March 3, 2022. The copyright holder for this preprint (which was not certified by peer review) is the author/funder, who has granted bioRxiv a license to display the preprint in perpetuity. It is made available under aCC-BY-ND 4.0 International license. 


\section{References}

1. L. Galluzzi et al., Molecular mechanisms of cell death: recommendations of the Nomenclature Committee on Cell Death 2018. Cell Death Differ 25, 486-541 (2018).

2. A. Herbert, A Genetic Instruction Code Based on DNA Conformation. Trends Genet 35, 887-890 (2019).

3. A. Herbert, Z-DNA and Z-RNA in human disease. Communications Biology 2, 7 (2019).

4. P. S. Ho, Thermogenomics: thermodynamic-based approaches to genomic analyses of DNA structure. Methods 47, 159-167 (2009).

5. P. J. Nichols et al., Recognition of non-CpG repeats in Alu and ribosomal RNAs by the Z-RNA binding domain of ADAR1 induces A-Z junctions. Nat Commun 12, (2021).

6. A. Herbert et al., A Z-DNA binding domain present in the human editing enzyme, doublestranded RNA adenosine deaminase. Proc Natl Acad Sci U S A 94, 8421-8426 (1997).

7. A. Athanasiadis, Z $\alpha$-domains: At the intersection between RNA editing and innate immunity. Seminars in Cell \& Developmental Biology 23, 275-280 (2012).

8. H. Guo et al., Herpes simplex virus suppresses necroptosis in human cells. Cell Host Microbe 17, 243-251 (2015).

9. Z. Huang et al., RIP1/RIP3 binding to HSV-1 ICP6 initiates necroptosis to restrict virus propagation in mice. Cell Host Microbe 17, 229-242 (2015).

10. X. Sun, J. Yin, M. A. Starovasnik, W. J. Fairbrother, V. M. Dixit, Identification of a novel homotypic interaction motif required for the phosphorylation of receptor-interacting protein (RIP) by RIP3. J Biol Chem 277, 9505-9511 (2002).

11. F. K. Chan, N. F. Luz, K. Moriwaki, Programmed necrosis in the cross talk of cell death and inflammation. Annu Rev Immunol 33, 79-106 (2015).

12. T. Zhang et al., Influenza Virus Z-RNAs Induce ZBP1-Mediated Necroptosis. Cell 180, 1115-1129 (2020).

13. S. Balachandran, E. S. Mocarski, Viral Z-RNA triggers ZBP1-dependent cell death. Current Opinion in Virology 51, 134-140 (2021).

14. H. Koehler et al., Vaccinia virus E3 prevents sensing of Z-RNA to block ZBP1-dependent necroptosis. Cell Host Microbe, (2021).

15. E. S. Mocarski, W. J. Kaiser, D. Livingston-Rosanoff, J. W. Upton, L. P. Daley-Bauer, True grit: programmed necrosis in antiviral host defense, inflammation, and immunogenicity. J Immunol 192, 2019-2026 (2014).

16. T. S. Bayer, L. N. Booth, S. M. Knudsen, A. D. Ellington, Arginine-rich motifs present multiple interfaces for specific binding by RNA. Rna 11, 1848-1857 (2005).

17. J.-L. E. P. H. Darlix et al., Mechanism of Nucleic Acid Unwinding by SARS-CoV Helicase. PLoS One 7, (2012).

18. J. A. Newman et al., Structure, mechanism and crystallographic fragment screening of the SARSCoV-2 NSP13 helicase. Nat Commun 12, 4848 (2021).

19. J. Chen et al., Structural Basis for Helicase-Polymerase Coupling in the SARS-CoV-2 ReplicationTranscription Complex. Cell 182, 1560-1573 e1513 (2020).

20. J. Chen et al., Ensemble cryo-electron microscopy reveals conformational states of the nsp13 helicase in the SARS-CoV-2 helicase replication-transcription complex. bioRxiv, 2021.2011.2010.468168 (2021).

21. M. Mompean et al., The Structure of the Necrosome RIPK1-RIPK3 Core, a Human HeteroAmyloid Signaling Complex. Cell 173, 1244-1253 e1210 (2018). 
22. S. N. Palmer, S. Chappidi, C. Pinkham, D. C. Hancks, T. Leitner, Evolutionary Profile for (Host and Viral) MLKL Indicates Its Activities as a Battlefront for Extensive Counteradaptation. Mol Biol Evol 38, 5405-5422 (2021).

23. R. Lorenz et al., ViennaRNA Package 2.0. Algorithms Mol Biol 6, 26 (2011).

24. R. C. Edgar, MUSCLE: multiple sequence alignment with high accuracy and high throughput. Nucleic Acids Res 32, 1792-1797 (2004).

25. A. S. Rose, P. W. Hildebrand, NGL Viewer: a web application for molecular visualization. Nucleic Acids Res 43, W576-579 (2015).

26. T. Schwartz, M. A. Rould, K. Lowenhaupt, A. Herbert, A. Rich, Crystal structure of the Za domain of the human editing enzyme ADAR1 bound to left-handed Z-DNA. Science 284, 1841-1845 (1999). 
bioRxiv preprint doi: https://doi.org/10.1101/2022.03.03.482810; this version posted March 3, 2022. The copyright holder for this preprint (which was not certified by peer review) is the author/funder, who has granted bioRxiv a license to display the preprint in perpetuity. It is made available under aCC-BY-ND 4.0 International license.

A. Human Pathogen
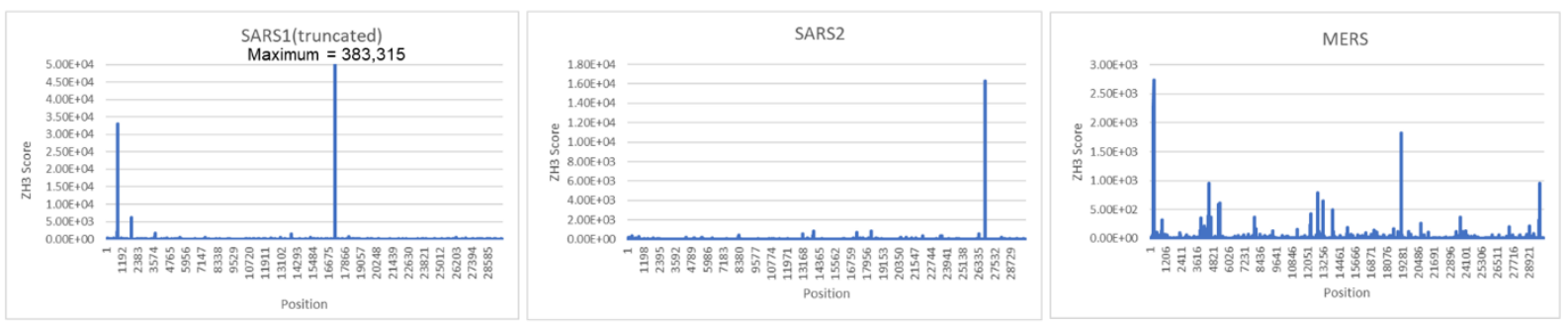

\section{B. Natural Host}
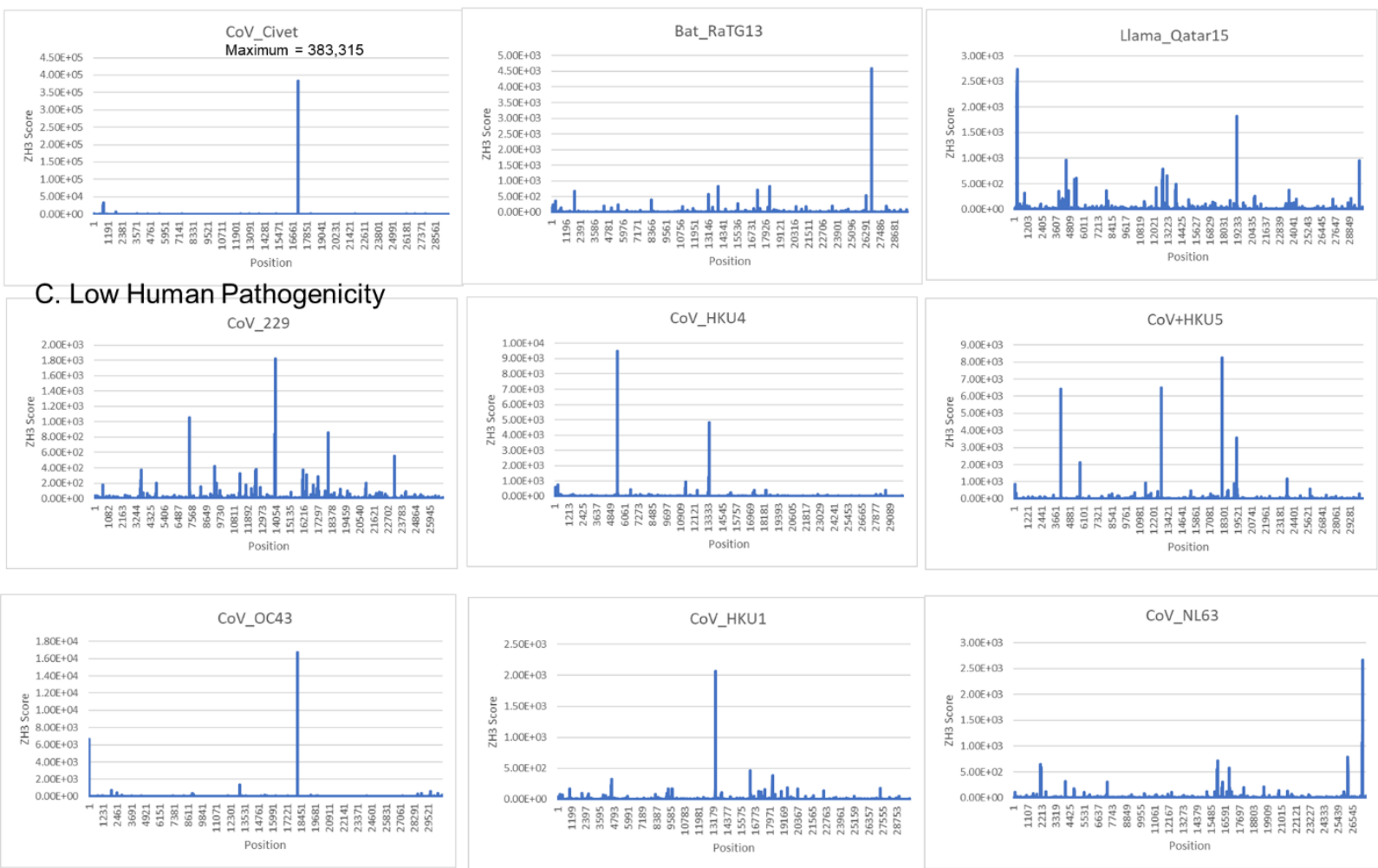

\section{Other Coronavirus Hosts}
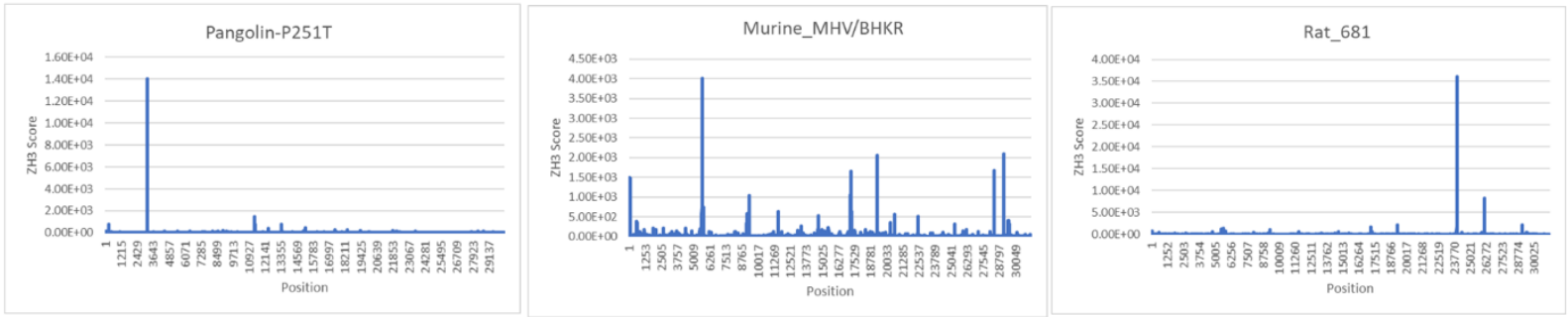

Figure 1. Coronavirus Signatures based on Z-flipons A. The signatures for each human pathogenic virus are unique. B. The signature match those for the presumed natural hosts for these viruses. $\mathbf{C}$. The signature differs from other known coronaviruses $D$. The viral signature also varies with the host animal infected. The signature is derived using the ZHUNT3 (ZH3) program (4) that scores the propensity of 
bioRxiv preprint doi: https://doi.org/10.1101/2022.03.03.482810; this version posted March 3, 2022. The copyright holder for this preprint (which was not certified by peer review) is the author/funder, who has granted bioRxiv a license to display the preprint in perpetuity. It is made available under aCC-BY-ND 4.0 International license.

sequences to flip to the left-handed helical Z-conformation. Sequences with a score about 700 are likely to adopt the Z-conformation under physiological conditions. 
A atcatacctgcgcotgcgcgcgtagag

$\begin{array}{llllllllll}I & I & P & A & R & A & R & V & E\end{array}$

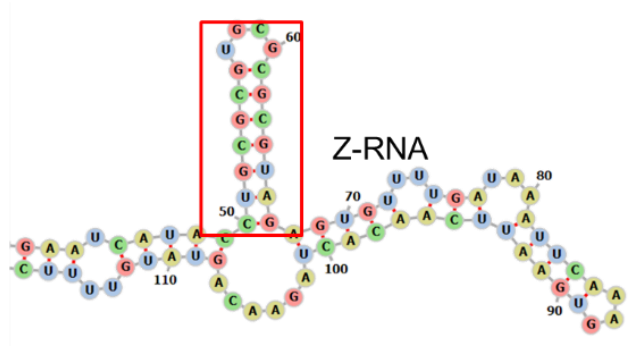

D

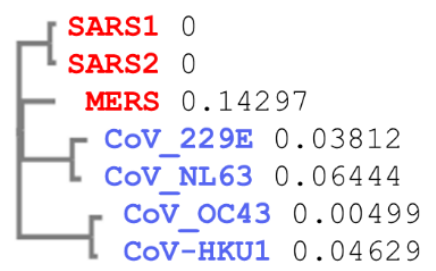

B. attatacctgcacgtgctcgtgtagag

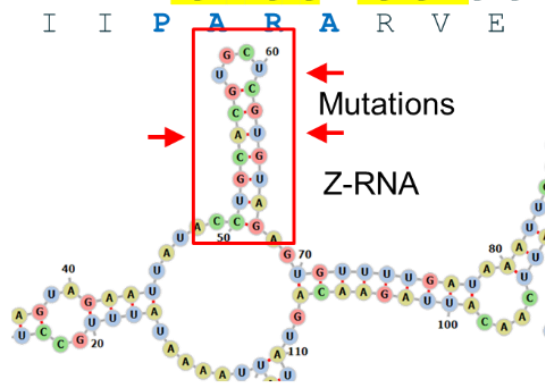

C. atcattcctgcaaaggcacgtgttgag
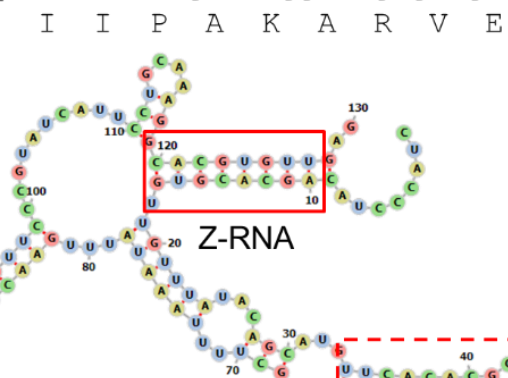

\section{E}

SARS1

SARS2

MERS

CoV 229E

$\mathrm{COV}-\mathrm{NL} 63$

$\mathrm{COV}-\mathrm{OC} 43$

COV-HKU1

NRNYVFTGYRVTKNSKVOIGEYTFEKGDYG-DAVVYRGTT NRNYVFTGYRVTKNSKVQIGEYTFEKGDYG-DAVVYRGTT NRNYVFTGYHITKNSKVQLGEYIFERIDYS-DAVSYKSST NRNSVFTCFQITKDSKFQVGEFVFEKVDYGSDTVTYKSTA NRNSVFTCFQISKDSKFQIGEFIFEKVEYGSDTVTYKSTNKNYVFTGYHFTKNGKTVLGEYVFDKSELT-NGVYYRATT

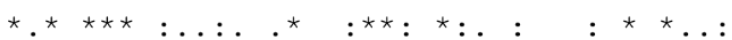

Figure 2 Nsp13 and Z-dependent necroptosis A. The high scoring ZH3 peak in SARS (NC_004718.3) maps to Nsp13 and encodes an arginine rich peptide with potential to bind to Z-RNA. Potential Z-RNA forming sequences are highlighted in yellow and form the Z-RNA stem within the red box identified using RNAfold (23). B. In SARS2 (NC_045512.2), three non-synonymous mutations conserve the Z-RNA stem and the peptide sequence, but diminish the Z-forming potential $\mathbf{C}$. The equivalent Nsp13 region in MERS has a different peptide sequence. The Z-RNA forming element is encoded immediately after this sequence block, with another Z-RNA element close-by (in dashed box) D. Phylogram showing the evolutionary distance between coronavirus strains with high (in red) and low (in blue) human pathogenicity. E. The sequence aligner MUSCLE (24) reveals that highly pathogenic coronaviruses have a conserved RHIM domain in NSP13 (in red) 

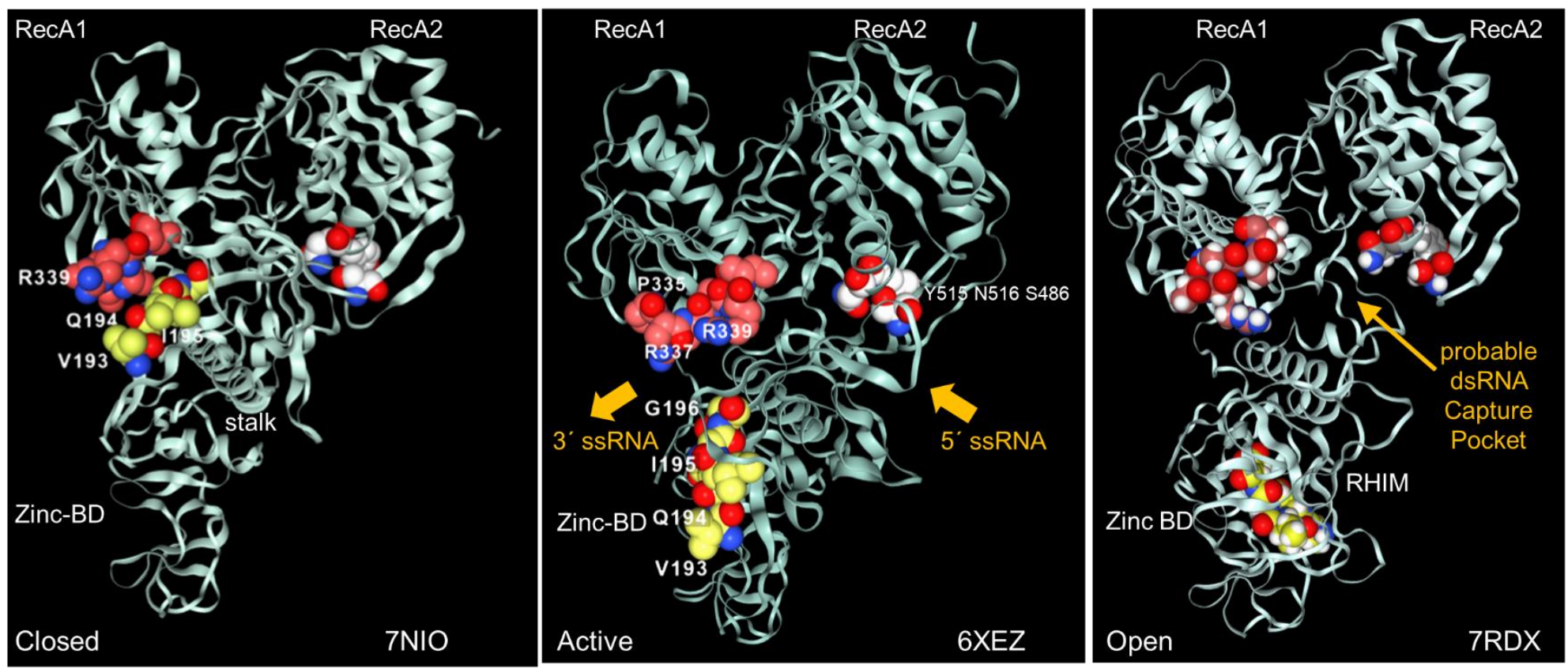

Figure 3 The interaction between the Nsp13 RHIM (residues 193-6) and TPARAR (residues 335-9) are conformation dependent. A. the ATP-free apo form of Nsp13, the RHIM (yellow space fill carbons) contacts PARAR339 (crimson space fill carbons) B. In the active state, RHIM and PARAR separate, opening the $5^{\prime}$ end of the single-strand RNA channel, that has the 3'end marked by N516 (white space fill carbons). C. The open complex in which the RHIM separates from the RecA2 domains to create a cavity that is large enough to accommodate dsRNA. This opening is associated with a rotation of the Zinc binding domain (ZincBD) relative to N516. PARAR also rotates, changing the position of R337 and R339. The structures are from PDB files 7NIO (18), 6XEZ (19) and 7RDX (20) as labeled, with images rendered using the NGLViewer (25). 

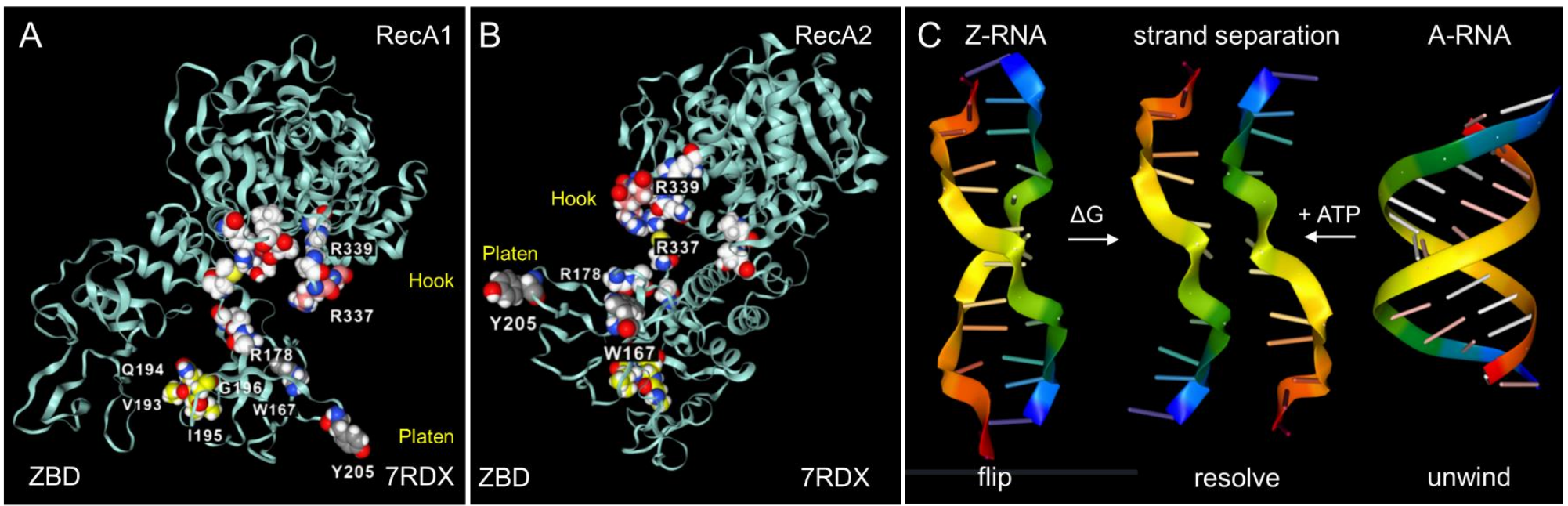

Figure 4 Nsp13 opens to expose a hook and platen. A The arginine rich PARAR hook (crimson carbons) and the tyrosine (Y205, grey carbons) platen create a surface for docking to dsRNA. Tryptophan (W168)(blue carbons) has the potential to orientate a to create a Z-RNA specific recognition element like that present in the Z $\alpha$ domain (26). The RHIM domain (yellow carbons) is free to engage other RHIM proteins. The space fill with white carbons show the residues identified as making base-specific contacts with single-stranded RNA in the active conformation shown in Figure 3B (residues 178, 179, 230, 233 in domain 1B, residues 311, 335,361, 362:E,363, 390, 408, 410:E in RecA1). C. In addition to the ATP-dependent helicase activity, Nsp13 has the potential to capture single stranded RNA when Z-RNA flips to and from A-RNA. The higher energy Z-RNA powers the strand-separation, providing the $\Delta G$ needed to fuel Z-flipon helicase activity. 